\title{
DESIGN OF A PORTABLE FOUNDRY SAND MIXER
}

\author{
Kaburu, Michael Kimani \\ Dept. of Industrial and Energy \\ Engineering, Egerton University, \\ Nakuru, Kenya
}

\author{
Owino, George Omollo \\ Dept. of Industrial and Energy \\ Engineering, Egerton University, \\ Nakuru, Kenya
}

\author{
Chirchir D. K \\ Dep mechanical Engineering \\ Multimedia University of Kenya, \\ Nairobi, Kenya
}

\begin{abstract}
Molding sand mixer is an effort towards mechanization of sand preparation in a foundry workshop. It's used to evenly and uniformly mix foundry sand with binders and water in given proportions to attain the required state and moisture. There are varieties of equipments and methods available to achieve this ranging from simple devices to completely mechanized units including electric powered machines. The degree to which a foundry can be mechanized depends almost entirely on economics of operations rather than availability or lack of a particular piece of equipment. With an auger screw simply pour the dry sand on top of a hopper adding water and bidders at the required quantities the turn the handle clockwise, no standing time required as the mixture rapidly mixes the material whilst keeping the body of the sand fluffy and light all in one simple action then straight into the molding box through a sprout. The overall objective of the project was to design, fabricate and test a portable foundry sand mixer which is affordable and locally manufactured and assembled using less power for small scale enterprises in the field of foundry engineering. Also use the same kind of machine in learning institutions like the technical colleges and universities foundry workshops for demonstration and practical activities.
\end{abstract}

Keywords: Design, fabricate, foundry, sand mixer,

\section{INTRODUCTION}

Foundry is a fundamental source of structural components for our Industrial Civilization. Thousands of foundries produce annually, millions of tonnes of ferrous and non-ferrous casting. In foundry, casting as a method for shaping metals dates back in $4000 \mathrm{BC}$, when arrow heads of copper were found to be easily shaped into required sizes by casting than forging process. The first and foremost step in sand casting process is the preparation of molding sand. This preparation basically constitutes sieving and mixing of foundry sand. If the quality of the final casting is to be ensured, then appropriate sieving, even and uniform mixing of sand with bindles and water should be guaranteed among other considerable factors. Most of small scale foundry enterprises in Kenya mix foundry sand manually. The same manual work (using shovel on a flat ground) is done in learning institutions workshops. This is tedious time consuming, less efficient and not very practical. Therefore the design project proposal is to address the above needs for a suitable sand mixing machine once its fabricated and tested in the university workshop.
Foundry sand mixture available in the market are bulky expensive and need a lot of energy to run leading to shovel mixing which is less effective tedious and unreliable contaminating the foundry sand with metals and other impurities. Thus there is challenge to design fabricate a cost effective and locally manufactured foundry sand mixer which is manually operated producing a homogenous mixture and free from contamination to have quality castings free from defects.

\section{LITERATURE REVIEW}

\subsection{Foundry Sand}

Foundry sand consists primarily of clean, uniformly sized, highquality silica sand or lake sand that is bonded to form molds for ferrous (iron and steel) and nonferrous (copper, aluminum, brass) metal castings. Although these sands are clean prior to use, after casting they may contain Ferrous (iron and steel) industries account for approximately 95 percent of foundry sand used for castings.

\subsubsection{Particle Shape}

The grain size distribution of spent foundry sand is very uniform, with approximately 85 to 95 percent of the material between 0.6 $\mathrm{mm}$ and $0.15 \mathrm{~mm}$ (No. 30 and No. 100) sieve sizes. The grains are generally rounded to sub angular in shape.

\subsubsection{Gradation}

The gradation tends to fall within the limits for a poorly graded fine sand that has relatively uniform size (passing $0.3 \mathrm{~mm}$ and retained $0.15 \mathrm{~mm}$ ), with fines content (less than $0.075 \mathrm{~mm}$ (No. $30-100$ sieve)) ranging from 5 to $15 \%$

\subsubsection{Durability}

Foundry sands display good durability characteristics with resistance to weathering.

\subsubsection{Plasticity}

Spent foundry sand generated by foundries using green sand molding systems, in which bentonite clay and sea coal are added to the casting, should be examined to ensure that plasticity levels comply with requirements for fine aggregates.

\subsubsection{Stripping}

Spent foundry sand is composed primarily of silica sand, coated with a thin film of burnt carbon, residual binder (bentonite, sea coal, resins), and dust. The hydrophilic nature of the (primarily silica) foundry sand, however, can result in stripping of the asphalt cement coating surrounding the aggregate grains, with resulting loss of fine aggregate and accelerated pavement deterioration. This problem can be mitigated by limiting the 
content of spent foundry sand in the mix to 15 percent of the total mass of aggregate or using an antistripping additive.

- $\quad$ Spent foundry sand typical characteristics: pH-7-9.

- Friction angle $32-40^{\circ}$

- $\quad$ Sieve analysis - less than 5\% passing a No. 200.

- Maximum dry density - $122 \mathrm{pcf}$

- Resistivity - 5,600 ohms-cm

- $\mathrm{Naso}_{4}$ loudness - 35 loss

- $\quad$ Particle density $-2.61 \mathrm{~g} / \mathrm{cc}$

- Bulk density - $1.54 \mathrm{~g} / \mathrm{cc}(2590) \mathrm{Kg} / \mathrm{M}^{3}$

- Coefficient of permeability $-10^{-3}-10^{-6} \mathrm{~cm} / \mathrm{sec}$ (AASHTO T21S/ASTM D2434)

- $\quad$ Moisture content - 0.1-10.1\% (ASTM D2216)

The various types of sand used in foundry for manufacture of moulds include

- Green sand naturally occurring and widely used.

- Other forms of dry sand, core sand, cement bonded sand and shell molding are also used for specific purpose.

Sand suitable for molding consists largely of silica together with sufficient clay (usually between 5-20\%) to act as binding materials. A naturally occurring sand of this type need only be mixed with sufficient water to facilitate molding. Molding sand must fulfill the following:-

- Must be sufficiently refractory to withstand the temperature of molten metal.

- Must contain sufficient bonding material to retain the shape of the mould and the bonding material itself must be refractory.

- It must be sufficiently permeable to allow gases which are produced to escape. Initial moisture content has to be effectively controlled when a mould with a harder surface which will resist erosion by the molten metal required. Skin dried moulds are often used. Then an additional binder such as molasses, resin, linseed oil or corn flower is either incorporated in the facing sand or sprayed on the surface of the mould cavity.

The recommended foundry sand mixture ratios are as follows:-

- $\quad$ Sand (by weight) $\quad-95.8 \%$

- Cereal/wood flour $-1.01 \%$

- Core oil $\quad-1.17 \%$

- Water $\quad-1.86 \%$

- Binder $\quad-0.16 \%$

\subsection{Foundry Sand Mixers}

- Match plate molding machine

- Intensive mixer

- The Richards high speed pivotal mixer

- Kelsons intensive mixer

- Shovel mixing

\section{METHODOLOGY}

Schematic diagram of the mixer.

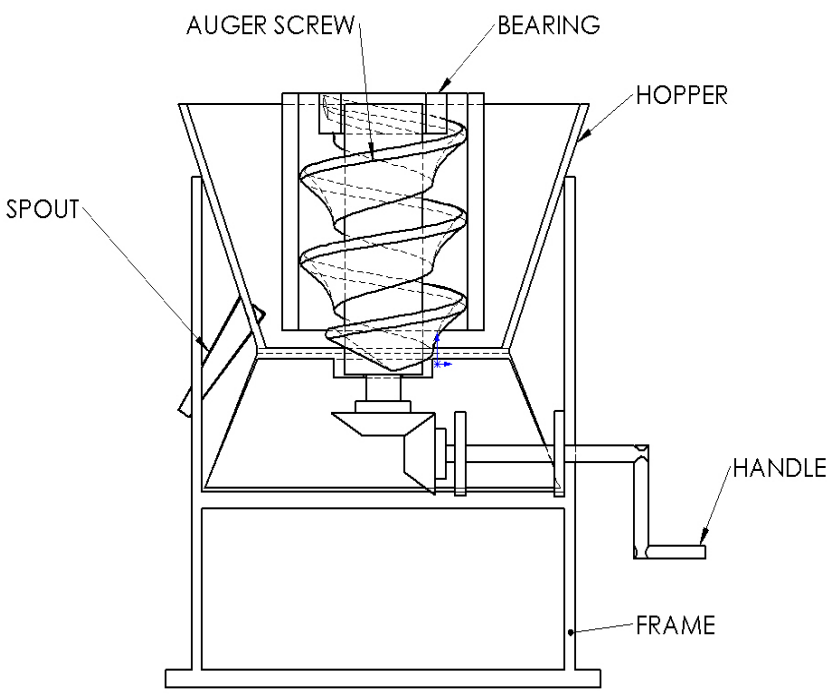

Figure 1: Schematic diagram of the mixer

\subsection{Machine Capacity}

The capacity and power of the auger screw.

$$
\begin{array}{r}
Q=\frac{\pi}{4}\left(D^{2}-d^{2}\right) P N=0.184 m^{3} / \mathrm{min} . \\
P=L Q \rho g=3.132 \mathrm{KW} .
\end{array}
$$

The maximum capacity of hopper when fully loaded:

$$
V=\frac{\pi h}{12}\left(D^{2}+D d+d^{2}\right)=\underline{0.1046 M^{3}}
$$

Overall machine capacity is determined as follows:

$$
C=V / t=\underline{1.743 \times 10^{-03} \mathrm{M}^{3} / \mathrm{sec}}
$$

\subsection{Equipments and tools.}

- The fabricated foundry sand mixer.

- Sieves no. 4-200 (4.76mm-75 $\mu \mathrm{m})$

- Sensitive balance to $0.1 \mathrm{~g}$.

- Timer.

- Ro-Tap shaker.

- Beaker to take the samples.

- Shovel. 


\subsection{Sieve Analysis}

Making a mechanical particle-size distribution of the foundry sand to check for homogeneity for different samples in one batch for the mixer and shovel mixing on the floor.

Table 1: Minimum mass sample

\begin{tabular}{|l|l|}
\hline SOIL SAMPLE SIZE & (ASTM D1140-54) \\
\hline $\begin{array}{l}\text { Nominal diameter largest } \\
\text { particle }\end{array}$ & Approximate minimum \\
mass of sample, $g$ \\
\hline - No. 10 sieve & -200 \\
\hline - No. 4 sieve & -500 \\
\hline$-3 / 4$ inch & -1500 \\
\hline
\end{tabular}

Table 2: Sieve standard sizes

\begin{tabular}{|l|l|}
\hline SIEVE NO. & SIZE (mm) \\
\hline 4 & 4.76 \\
\hline 10 & 2 \\
\hline 20 & 0.85 \\
\hline 40 & 0.425 \\
\hline 60 & 0.25 \\
\hline 100 & 0.15 \\
\hline 200 & 0.075 \\
\hline
\end{tabular}

The sieve numbers were used earlier in the British systems but currently the metric system is used to indicate the maximum grain size that can go through the sieve at one given time.

Table 3: Shows \% mass retained after conducting a sieve analysis

\begin{tabular}{|r|r|r|r|r|r|r|r|}
\hline \multirow{2}{*}{$\begin{array}{l}\text { Sieve } \\
\text { no. }\end{array}$} & \multicolumn{6}{|l|}{ \% Mass retained } \\
\cline { 2 - 8 } & $\mathbf{0 ~ s}$ & $\mathbf{2 0} \mathbf{~ s}$ & $\mathbf{4 0 ~ s}$ & $\mathbf{6 0} \mathbf{~ s}$ & $\mathbf{8 0} \mathbf{~ s}$ & $\mathbf{1 0 0} \mathbf{~ s}$ & $\mathbf{1 2 0} \mathbf{~ s}$ \\
\hline $\mathbf{4}$ & 0.2 & 0.2 & 0.1 & 0.3 & 0.3 & 0.1 & 0.2 \\
\hline $\mathbf{1 0}$ & 19 & 20.4 & 21.6 & 21.6 & 21.8 & 21.8 & 21.8 \\
\hline $\mathbf{2 0}$ & 19 & 20.4 & 21.6 & 21.6 & 21.8 & 21.8 & 21.8 \\
\hline
\end{tabular}

DOI: 10.21276/ijirem.2016.3.6.13

\begin{tabular}{|r|r|r|r|r|r|r|r|}
$\mathbf{4 0}$ & 17 & 17 & 17 & 17.1 & 17.2 & 17.3 & 17.3 \\
\hline $\mathbf{6 0}$ & 21.3 & 21.2 & 21.6 & 21.5 & 21.4 & 21.4 & 21.4 \\
\hline $\mathbf{1 0 0}$ & 10 & 10.3 & 10.2 & 10.1 & 10.1 & 10 & 10.1 \\
\hline $\mathbf{2 0 0}$ & 6.6 & 6 & 5.8 & 5.8 & 5.8 & 5.7 & 5.7 \\
\hline Pan & 3.7 & 3.4 & 2.6 & 2.6 & 2.5 & 2.6 & 2.5 \\
\hline
\end{tabular}

Table 3 Shows \% mass retained after conducting a sieve analysis from samples of foundry sand mixed using the newly fabricated mixer. First the mass of empty sieves is measured then mass of sieve and material and the difference recorded. The \% mass retained is calculated

with constant samples of $500 \mathrm{~g}$. A graph is plotted \% mass retained in a time of $20 \mathrm{sec}$ against different sieves.

A) SIEVE ANALYSIS FOR THE MIXER

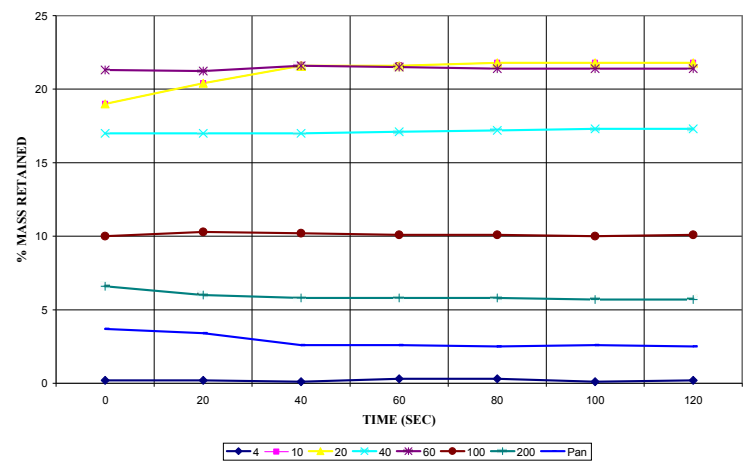

Figure 2: Mass retained against time for mixer

Table 4: Sieve analysis data for shovel mixing

\begin{tabular}{|r|r|r|r|r|r|r|r|}
\hline \multirow{2}{*}{$\begin{array}{c}\text { Sieve } \\
\text { no. }\end{array}$} & \multicolumn{6}{|l}{ \% Mass retained } \\
\cline { 2 - 8 } & $\mathbf{0 ~ s}$ & $\mathbf{2 0} \mathbf{4}$ & $\mathbf{4 0} \mathbf{6}$ & $\mathbf{6 0} \mathbf{8}$ & $\mathbf{8 0} \mathbf{1 0 0}$ & $\mathbf{1 2 0} \mathbf{~ s}$ \\
\hline $\mathbf{4}$ & 1 & 0.5 & 0.72 & 0.5 & 0.6 & 0.4 & 0.7 \\
\hline $\mathbf{1 0}$ & 34.5 & 28.5 & 29.44 & 28 & 24.3 & 25 & 30.8 \\
\hline $\mathbf{2 0}$ & 19.2 & 16.9 & 18.72 & 18.8 & 19.1 & 18.1 & 18.5 \\
\hline $\mathbf{4 0}$ & 18.7 & 20.5 & 20.92 & 21.5 & 25.6 & 19.3 & 17.8 \\
\hline $\mathbf{6 0}$ & 13.2 & 16.3 & 14.9 & 17.2 & 13.1 & 18.2 & 16.7 \\
\hline $\mathbf{1 0 0}$ & 1.3 & 4.5 & 8.04 & 9.3 & 10.7 & 9.1 & 8.7 \\
\hline $\mathbf{2 0 0}$ & 5.2 & 9.2 & 5.7 & 2.3 & 4.3 & 6.6 & 4.7 \\
\hline Pan & 7 & 3.6 & 1.56 & 2.2 & 2.3 & 3.3 & 4.7 \\
\hline
\end{tabular}




\section{DESIGN OF A PORTABLE FOUNDRY SAND MIXER}

Table 4.2 Shows \% mass retained after conducting a sieve analysis from samples of foundry sand mixed using a shovel on the floor. First the mass of empty sieves is measured then mass of sieve and material and the difference recorded. The \% mass retained is calculated

with constant samples of $500 \mathrm{~g}$. A graph is plotted \% mass retained in a time of $20 \mathrm{sec}$ against different sieves.

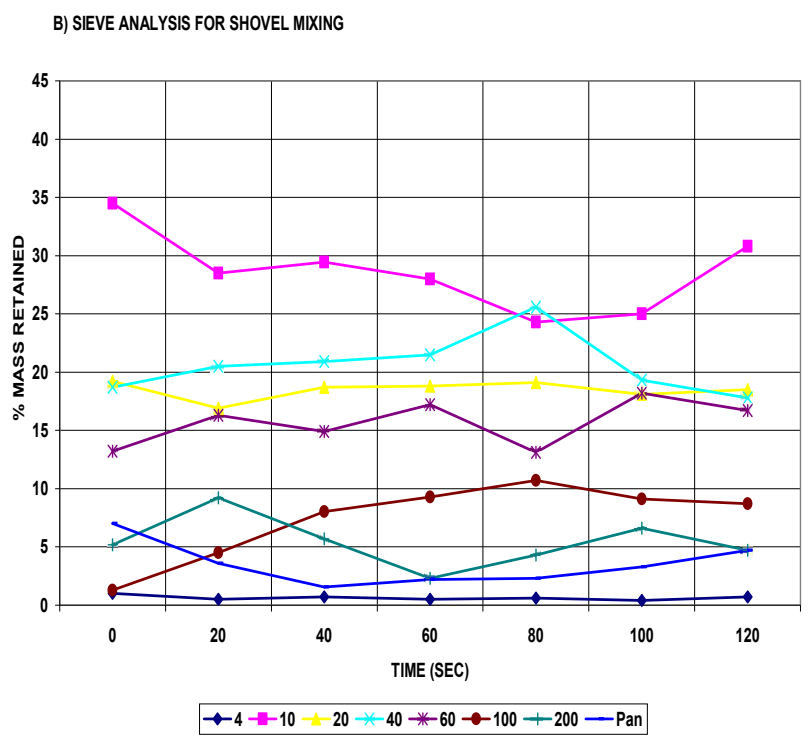

Figure 3: \% Mass retained against time for shovel

Table 5: Sieves no. 40, 60 and 200 compared

\begin{tabular}{|c|c|c|c|c|c|c|c|}
\hline \multirow{2}{*}{$\begin{array}{c}\text { Sieve } \\
\text { no. }\end{array}$} & \multicolumn{5}{|c|}{$\%$ Mass retained } & & \\
\hline & $0 \mathrm{~s}$ & $20 \mathrm{~s}$ & $40 \mathrm{~s}$ & $60 \mathrm{~s}$ & $80 \mathrm{~s}$ & $100 \mathrm{~s}$ & $120 \mathrm{~s}$ \\
\hline $40 \mathrm{~m}$ & 17 & 17 & 17 & 17.1 & 17.2 & 17.3 & 17.3 \\
\hline $40 \mathrm{~s}$ & 18.7 & 20.5 & 20.92 & 21.5 & 25.6 & 19.3 & 17.8 \\
\hline $60 \mathrm{~m}$ & 21.3 & 21.2 & 21.6 & 21.5 & 21.4 & 21.4 & 21.4 \\
\hline $60 \mathrm{~s}$ & 13.2 & 16.3 & 14.9 & 17.2 & 13.1 & 18.2 & 16.7 \\
\hline $200 \mathrm{~m}$ & 6.6 & 6 & 5.8 & 5.8 & 5.8 & 5.7 & 5.7 \\
\hline $200 \mathrm{~s}$ & 5.2 & 9.2 & 5.7 & 2.3 & 4.3 & 6.6 & 4.7 \\
\hline
\end{tabular}

Key: $\mathrm{m}$ - Mixer

s - Shovel
C) MIXER AND SHOVEL GRAPHS

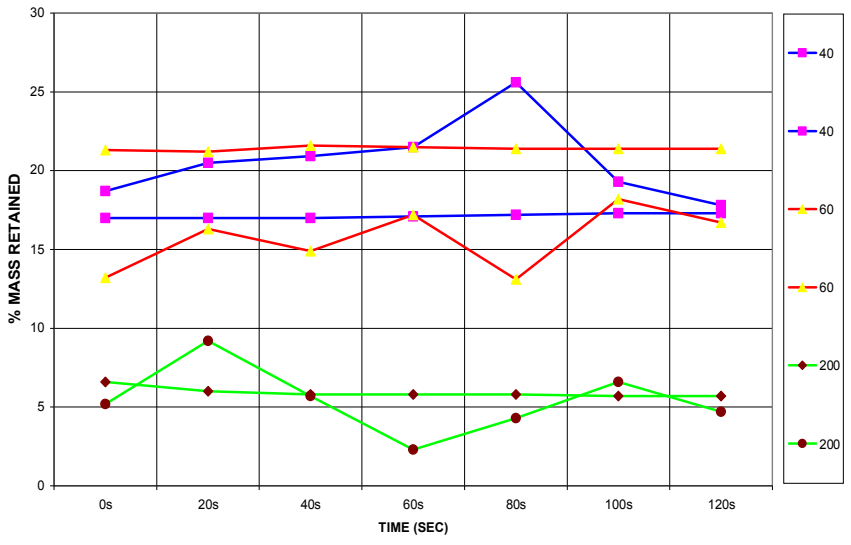

Figure 4: \% Mass retained against time for mixer and shovel

The sieves number 40, 60 and 200 are compared in the above graph for clarity. The shovel mixing graph is fluctuating with time and whiles the one for mixer is constant. The finer the sieve the lesser the mass retained.

\section{RESULTS AND DISCUSSION}

\subsection{The mixer}

After running the mixer at a speed of one revolution per minute optimal results were well displayed after $60-80 \mathrm{sec}$. Above that, the graph stabilizes to almost a constant mass retained in the sieves hence showing homogeneity.

\subsection{The shovel mixing}

After mixing the sand within the stipulated time of $20 \mathrm{sec}$, the mass retained in the sieves was not stable compared to the same time taken by the mixer. Meaning it takes longer time to homogenously mix the sand compared to the mixer which takes $60-80 \mathrm{sec}$ for $70 \mathrm{~kg}$ batch.

\section{CONCLUSION}

The research project was successful as I was able to design, fabricate and test the performance of a cheap portable foundry sand mixer. This poses a great challenge to shovel mixing as the material is also subjected to contamination as much is done on the ground which my contain other elements. The design can be manufactured locally and sold at a price of about Ksh. 25,000 to Ksh. 30,000 as the materials are locally available. The mixer is best suited to small scale entrepreneurs and colleges workshops where energy is not guaranteed all the time.

\section{RECOMMEDATIONS}

- Other tests to be investigated further on the mixture are like permeability test and compaction tests.

- Analysis of the effect of different revolutions speeds in relation to homogeneity of the mixture in a given time.

- The driving system to be motorized for higher efficiency.

- Provision for a top cover to prevent air pollution with dust

- An improved gearbox and lubrication system. 


\section{REFERENCES}

1) Black B. J. (2004). Workshop Processes, Practices and materials. Elsevier's Science and Technology Right Department in Oxford U.K.

2) Bhandari, V. B. (1994). Design of machine elements. Tata McGraw-Hill, New Delhi

3) Bowles, J. E. (1992). Engineering properties of soils and their measurements, $4^{\text {th }}$ Ed, McGraw- Hill.INC.NY.

4) De Garmo, E. P. (1997). Material and processes in manufacturing. Asoke, K. Ghosh, New Delhi.

5) Hearn, E. J. (1997). Mechanics of materials, Butterworth Heinemann, New Delhi.

6) Jain, R.K., and Gupta, S.C. (1984). Production Technology, Khanna, New Delhi.

7) Kulkani, S. G. (1997). Machine design, Tata McGraw-Hill, New Delhi.

8) Perry, H. (1976). Agricultural Process Engineering. The AVI, Westport, Connecticut.

9) Short, B. C. (1976). Workshop Technology. Cassell \& Collier Macmillan, New York.

10) Tata McGraw Hill, (1982). Machine Tool Design. Tata McGraw Hill; New Delhi. 